\title{
Effect of Aerobic Exercise with and without Green Coffee Supplementation on Serum Apolipoprotein B and Atherogenic Indices of Overweight Men
}

Farida Fazel (PhD Candidate) $\mathrm{PhD}$ student of Exercise Physiology, Department of Exercise Physiology, Islamic Azad University, Neyshabur Branch, Iran

Artmis Naghibzadeh (PhD

Candidate)

PhD student of Exercise Physiology, Department of Exercise Physiology, Islamic Azad University, Neyshabur Branch, Iran

Mohammad Reza Ramezanpour (PhD)

Associate Professor, Department of Exercise Physiology, Islamic Azad University, Mashhad Branch, Iran

Reza Bagheri (MSc)

MSc of Applied Exercise Physiology, Department of Exercise Physiology, Faculty of Sports Sciences, Ferdowsi University of Mashhad, Mashhad, Iran

Azar Hamidi (PhD Candidate)

$\mathrm{PhD}$ student of Exercise Physiology, Department of Exercise Physiology, Islamic Azad University, Neyshabur Branch, Iran

Amir Rashidlamir (PhD)

Associate Professor, Department of Exercise Physiology, Faculty of Sports Sciences, Ferdowsi University of Mashhad, Mashhad, Iran

Corresponding author: Amir Rashidlamir

Email: rashidlamir@um.ac.ir

Tel: +98-9151514174

Address: Department of Sports

Physiology, Faculty of Sports

Sciences, Ferdowsi University of

Mashhad, Mashhad, Iran

Received: 30 Jun 2018

Revised: 02 Sep 2018

Accepted: 29 Sep 2018

(c) (i) (9)

This work is licensed under a Creative

Commons Attribution 4.0 License.

\begin{abstract}
Background and Objectives: Coronary heart disease has a direct correlation with plasma levels of Apolipoprotein B (ApoB) and low-density lipoprotein (LDL) and an inverse relationship with high-density lipoprotein (HDL) level. This study aimed at comparing effect of eight weeks of aerobic training with and without green coffee supplementation on serum ApoB level and atherogenic indices of overweight men.

Methods: Thirty overweight men were randomly divided into two groups: training + green coffee supplementation $(T+6 ; n=15)$ and training + placebo $(T+P ; n=15)$. Participants in both groups performed aerobic training, three sessions per week for eight weeks. Initial exercise intensity was set at $50 \%$ of maximum heart rate but gradually increased to $75 \%$ of maximum heart rate in the last two weeks. In a single-blind design, the subjects in the $\mathrm{T}+\mathrm{G}$ group received a $400 \mathrm{mg}$ capsule of green coffee bean extract one hour before each exercise session. The $\mathrm{T}+\mathrm{P}$ group received placebo at the same time. Paired sample t-test and independent t-test were used to compare intra-group and inter-group variations, respectively. All statistical analyses were performed using SPSS (version 22) at significance level of 0.05 .
\end{abstract}

Results: ApoB, LDL/HDL and total cholesterol/HDL decreased significantly in both groups. However, the changes were more notable in the $\mathrm{T}+\mathrm{G}$ group compared to the $\mathrm{T}+\mathrm{P}$ group.

Conclusion: The eight-week training program along with green coffee supplementation has positive effects on serum ApoB and atherogenic indices of overweight, inactive men. Therefore, it can be suggested as a non-pharmacological method of preventing cardiovascular disease.

Keywords: Aerobic exercise, green coffee, 0verweight, Apolipoprotein b.

This paper should be cited as: Fazel F, Naghibzadeh A, Ramezanpour MR, Bagheri R, Hamidi A, Rashidlamir A[Effect of Aerobic Exercise with and without Green Coffee Supplementation on Serum Apolipoprotein $B$ and Atherogenic Indices of Overweight Men]. mljgoums. 2019; 13(3):20-24 


\section{INTRODUCTION}

Coronary artery disease (CAD) is a common obesity-associated cardiovascular disease (CVD) which has a direct correlation with high plasma level of low-density lipoprotein (VLDL and LDL) and decreased plasma level of high-density lipoprotein (HDL) (1). Physical activity is one of the factors that could alter lipid profile, especially HDL-cholesterol (HDL-C) and LDL (2). HDL-C plays an important role in prevention of CVD through reverse cholesterol transport (3), which involves removal and transporting excess cholesterol from peripheral tissues, including the wall of arteries and macrophages to the liver (4). Physical activity may reduce risk of mortality in obese individuals by reducing inflammation and coagulation factors. Aquatic exercise can reduce some CVD risk factors, such as apolipoprotein $b$ (ApoB) to apolipoprotein a (ApoA) ratio (5). Aerobic training can help lower weight, body fat percentage (BFP) and body mass index (BMI) in overweight women. Moreover, it significantly improves the reverse cholesterol transfer by increasing ApoA1 and decreasing ApoB concentrations, thus reducing the risk of developing atherosclerosis. Kadoglou et al. (2010) showed that 12 months of exercise increases HDL and decreases ApoB-100 levels (6). ApoB is a key structural protein of VLDL and LDL and a predictor of CAD (7). It is essential for binding of LDL to its receptor and ultimately cholesterol absorption (8).

Green coffee extract contains high concentrations of chlorogenic acid that affects lipid and glucose metabolism (9). In addition to reducing intestinal absorption of fat and accumulation of visceral fat, the extract increases the metabolism of fat in the liver (10). Chlorogenic acid helps increase the activity of a liver enzyme called carnitine palmityl transferase (11). Caffeine present in the green beans blocks adenosine receptors, thus increasing the amount of selenium monosaccharide (12). The extract inhibits cyclic nucleotide phosphodiesterases that convert cAMP to AMP, thereby increasing cAMP levels which in turn increases the activity of hormone-sensitive lipase, thus resulting in lipolysis (13). According to Naderi et al. (2018), eight weeks of combined training and green coffee supplementation affects secretion of adipokines, reduces adenosine level and insulin resistance and stimulates weight loss.

The present study aimed to determine effects of green coffee supplementation along with aerobic exercise on serum levels of ApoB and atherogenic indices of overweight men.

\section{MATERIALS AND METHODS}

This was a quasi-experimental study with a pre- and post-test design. Study population included 30 healthy, inactive and overweight young men. Inclusion criteria consisted BMI of $25-30 \mathrm{Kg} / \mathrm{m}^{2}$, no history of diabetes or cardiovascular, liver, kidney and lung disease and inactivity (lack of regular exercise). Exclusion criteria included use of any supplement or weight loss medication over the past six months. After obtaining consent from the participants, the subjects were randomly and equally divided into two groups: aerobic exercise-green coffee supplementation and aerobic exercise-placebo (control group). Those who did not participate in more than three sessions and not follow the training and supplementation instructions were excluded from the study. The INBODY 170 body composition analyzer (South Korea) was used to measure weight. Height of each subject was measured using a digital height gauge (SKAA, Germany). Heart rate of the participants was monitored using a Polar F1TM heart rate monitor (Finland). The subjects were asked not to take any supplements or medication before start of the training protocol. A meeting was held in order to explain the general purpose of the study and details of training protocols. In a single-blind design, the subjects in the exercise + supplementation group received a $400 \mathrm{mg}$ capsule of green coffee bean extract (Zist Takhmir Co., Iran) one hour before each exercise session. The control group received the same amount of placebo (14).

Exercise sessions were held three times a week and included 10 minutes of warming up (slow running and stretching), 30 minutes of aerobic exercise and 10 minutes of cool down (light stretching). In the first week, training intensity was set at 55\% of maximum heart rate, but was gradually increased to $75 \%$ of maximum heart rate at the end of each week by adding two minutes to the training duration so that at the end of the week the main training session lasted 44 minutes. After 12 hours of overnight fasting, venous 
blood samples $(5 \mathrm{~mL})$ were taken from each subject 48 hours before the first training session and 48 hours after the last training session.

The subjects were advised not to perform any physical activity for 36 hours prior to blood sampling.

Blood samples were collected in EDTA tubes and immediately centrifuged at $3000 \mathrm{rpm}$ for 10 minutes. Apo B, LDL-C, HDL and total cholesterol (TC) were measured by enzymatic method using photometric reading and Pars Azmun kits (Iran) with a sensitivity of $1 \mathrm{mg} / \mathrm{dl}$ and a coefficient of variation of $1.5 \%$.

The subjects were asked to maintain their dietary habits throughout the study. Data were analyzed using SPSS software (version 22). Mean and standard deviation (SD) were calculated after testing normality of data using the Shapiro-Wilk test. The Levene's test was also used to ensure the homogeneity of variances. Paired sample t-test and independent t-test were used to compare intragroup and inter-group variations, respectively. All statistical analyses were performed at significance level of 0.05 .

\section{RESULTS}

According to the outcomes, weight, BMI and BFP values decreased significantly $(\mathrm{p}=0.001)$. The Apo B and TC / HDL concentration decreased significantly in both groups $(\mathrm{P}=0.001),(\mathrm{P}=0.005)$ respectively. About the LDL / HDL ratio, we saw a significant difference between groups $(\mathrm{p}=0.029)$. Lean body mass increased in both groups, however was not statistically significant.

Table 1- The characteristics of the participants

\begin{tabular}{ccc}
\hline Groups & Age (years) & Height $($ Cm) \\
\hline Training + Green coffee & $\mathbf{2 5 . 2} \pm \mathbf{3 . 0 4}$ & $\mathbf{1 6 2} \pm \mathbf{2 . 0 5 8}$ \\
Training + Placebo & $\mathbf{2 6 . 2} \pm \mathbf{2 . 3 5}$ & $\mathbf{1 6 0} \pm \mathbf{1 . 0 6 3}$ \\
\hline
\end{tabular}

Table 2- Comparison of pre- and post-test value of body composition variables between the groups

\begin{tabular}{|c|c|c|c|c|c|c|c|}
\hline \multirow[t]{3}{*}{ Variable } & \multirow[t]{3}{*}{ Group } & \multirow[t]{3}{*}{ Pre-test } & \multirow[t]{3}{*}{ Post-test } & \multicolumn{4}{|c|}{ Variation } \\
\hline & & & & \multicolumn{2}{|c|}{ Intra-group } & \multicolumn{2}{|c|}{ Inter-group } \\
\hline & & & & $\mathbf{T}$ & $\mathbf{P}$ & $\mathbf{F}$ & $\mathbf{P}$ \\
\hline \multirow[t]{2}{*}{ Weight (Kg) } & Training + Green coffee & $71.71 \pm 6.05$ & $69.29 \pm 5.43$ & 6.51 & 0.00 & 49.59 & 0.001 \\
\hline & Training + Placebo & $66.49 \pm 8.37$ & $65.56 \pm 8.11$ & 3.047 & 0.014 & & \\
\hline \multirow[t]{2}{*}{ BMI $\left(\mathrm{Kg} / \mathrm{m}^{2}\right)$} & Training + Green coffee & $28.62 \pm 1.25$ & $27.70 \pm 0.01$ & 7.172 & 0.00 & 23.75 & 0.001 \\
\hline & Training + Placebo & $26.54 \pm 1.71$ & $25.98 \pm 1.63$ & 4.75 & 0.003 & & \\
\hline \multirow{2}{*}{$\begin{array}{c}\text { Skeletal muscle mass } \\
(\%)\end{array}$} & Training + Green coffee & $24.61 \pm 3.49$ & $25.35 \pm 3.85$ & 1.87 & 0.093 & 1.39 & 0.26 \\
\hline & Training + Placebo & $23.50 \pm 3.53$ & $23.66 \pm 3.64$ & 1.38 & 0.2 & & \\
\hline \multirow[t]{2}{*}{ BFP $(\%)$} & Training + Green coffee & $32.03 \pm 4.87$ & $27.96 \pm 3.34$ & 3.13 & 0.011 & 5.58 & 0.001 \\
\hline & Training + Placebo & $25.50 \pm 3.05$ & $25 \pm 3.01$ & 2.522 & 0.032 & & \\
\hline
\end{tabular}

Table 3- Comparison of pre- and post-test value of Apo B, TC/HDL and LDL/HDL between the groups

\begin{tabular}{|c|c|c|c|c|c|c|c|}
\hline \multirow[t]{3}{*}{ Variable } & \multirow[t]{3}{*}{ Group } & \multirow[t]{3}{*}{ Pre-test } & \multirow[t]{3}{*}{ Post-test } & \multicolumn{4}{|c|}{ Variation } \\
\hline & & & & \multicolumn{2}{|c|}{ Intra-group } & \multicolumn{2}{|c|}{ Intra-group } \\
\hline & & & & $\mathbf{T}$ & $\mathbf{P}$ & $\mathbf{F}$ & $\mathbf{P}$ \\
\hline \multirow[t]{2}{*}{ ApoB (ml/dc) } & Training + Green coffee & $88.12 \pm 2.66$ & $72.23 \pm 2.45$ & 6.05 & 0.00 & & \\
\hline & Training + Placebo & $86 \pm 2.25$ & $183 \pm 151$ & 5.81 & 0.005 & 6.30 & 0.001 \\
\hline \multirow[t]{2}{*}{ TC/HDL (ml/dc) } & Training + Green coffee & $4.59 \pm 1.02$ & $3.59 \pm 1.12$ & 5.08 & 0.000 & & \\
\hline & Training + Placebo & $4.37 \pm 0.93$ & $3.87 \pm 1.06$ & 2.48 & 0.03 & 3.98 & 0.005 \\
\hline \multirow[t]{2}{*}{ LDL/HDL (mg/dc) } & Training + Green coffee & $2.65 \pm 0.0654$ & $1.92 \pm 0.78$ & 3.87 & 0.002 & & \\
\hline & Training + Placebo & $2.57 \pm 0.93$ & $2.26 \pm 0.423$ & 2.32 & 0.04 & 3.58 & 0.029 \\
\hline
\end{tabular}

\section{DISCUSSION}

The aim of this study was to investigate the effect of eight weeks of aerobic training with and without green coffee supplementation on serum level of ApoB and atherogenic indices of overweight, inactive men. In our study, although training alone significantly decreased ApoB, LDL/HDL and TC/HDL ratio, but this decrease became more profound in the training and supplemnetaion group. Pourvaghar et al. (2012) studied the effect of a single session of intensive aerobic exercise on ApoA, ApoB and some serum lipid parameters of 26 participants. They observed a significant decrease in serum concentrations of LDL, ApoA and ApoB following high-intensity aerobic exercise(15). In study by Ketabi Poor et al. (2013) on effects of aquatic exercise on ApoA, ApoB and serum lipoproteins of obese and normal-weight menopausal women, the exercise training increased ApoA and decreased ApoB and ApoB/ApoA ratio. The study also reported a significant decrease in LDL levels following the water aerobic exercise (16). Banz et al. reported that 
cholesterol, LDL and triglyceride levels decrease significantly following endurance and resistance training (17). Ghorbanian et al. studied the effect of eight weeks combined interval endurance training on a daily basis of four 24-minute days, concluded that the TC, TG, LDL / HDL, TC / HDL and BMI decreased significantly (18). A moderateintensity exercise intervention significantly altered ApoA and ApoA/ApoB values, but did not affect ApoB (19). The difference between results of the mentioned study and our study could be due to the difference in characteristics of the subjects, weight, exercise intensity, age of participants and genetic factors. It has been shown that exercise along with diet restriction is the method of choice for treating obesity. Aerobic exercise can lower plasma concentrations of cholesterol, which prevents the early onset of CVD (20). According to Sugiura et al. (2002), exercise increases the activity of lipoprotein lipase (LPL) and lecithin cholesterol-acyltransferase (LCAT), which in turn lowers LDL, triglyceride and cholesterol levels (21).

Limited number of studies has investigated the effect of green coffee supplementation on

\section{REFERENCES}

1. Sahoo D, Trischuk TC, Chan T, Drover VA, Ho S, Chimini G, et al. ABCA1-dependent lipid efflux to apolipoprotein AI mediates HDL particle formation and decreases VLDL secretion from murine hepatocytes. Journal of lipid research. 2004; 45(6): 1122-31.

2. Fatone C, Guescini M, Balducci S, Battistoni S, Settequattrini A, Pippi R, et al. Two weekly sessions of combined aerobic and resistance exercise are sufficient to provide beneficial effects in subjects with Type 2 diabetes mellitus and metabolic syndrome. J Endocrinol Invest. 2010; 33(7): 489-95. doi: 10.3275/6814.

3. Oram JF. HDL apolipoproteins and ABCA1: partners in the removal of excess cellular cholesterol. Arterioscler Thromb Vasc Biol. 2003; 23(5): 720-7.

4. Lewis GF, Rader DJ. New insights into the regulation of HDL metabolism and reverse cholesterol transport. Circulation research. 2005; 96(12): 1221-32.

5. Ketabi Poor SM, Koushkie Jahromi M. Effeet of Aquatic Aerobic Training on Serum A and B Apoproteins and Lipoproteins in Obese and Normal Weight Menopause Women. J Arak Uni Med Sci. 2014, 17(8): 44-52.

6. Kadoglou NP, Iliadis F, Sailer N, Athanasiadou Z, Vitta I, Kapelouzou A, et al., Exercise training ameliorates the effects of rosiglitazone on traditional and novel cardiovascular risk factors in patients with type 2 diabetes mellitus. Metabolism-Clinical and Experimental. 2010; 59(4): 599-607. serum levels of ApoB and atherogenic indices. It is suggested that constituents of green coffee including caffeine and theophylline can act as antagonists of $\mathrm{A} 1$ and $\mathrm{A} 2$ receptor adenosine receptors and compete to inhibit activity of adenosine in different tissues of the body (22). By blocking adenosine receptors, caffeine also increases the amount of cyclic adenosine monophosphate, reduces production of free radicals and stimulates production of prostaglandins and anti-inflammatory cytokines.

\section{CONCLUSION}

The eight-week training program along with green coffee supplementation has positive effects on serum ApoB and atherogenic indices of overweight, inactive men. Therefore, it can be suggested as a nonpharmacological method of preventing CVDs.

\section{ACKNOWLEDGMENTS}

The authors would like to thank all those who cooperated with us in this research.

\section{CONFLICT OF INTEREST}

There is no conflict of interest to declare.

7. Walldius G, Jungner I. Apolipoprotein AI versus $H D L$ cholesterol in the prediction of risk for myocardial infarction and stroke. Curr Opin Cardiol. 2007; 22(4): 359-67.

8. Cromwell WC, Barringer TA. Low-density lipoprotein and apolipoprotein B: clinical use in patients with coronary heart disease. Curr Opin Cardiol. 2007; 22(4): $359-67$.

9. Murase T, Misawa K, Minegishi Y, Aoki M, Ominami $\mathrm{H}$, Suzuki Y, et al. Coffee polyphenols suppress dietinduced body fat accumulation by downregulating SREBP-1c and related molecules in C57BL/6J mice. Am J Physiol Endocrinol Metab. 2011; 300(1): E122-33. doi: 10.1152/ajpendo.00441.2010.

10. Troiano RP, Berrigan D, Dodd KW, Masse LC, Tilert T, McDowell M. Physical activity in the United States measured by accelerometer. Medicine and science in sports and exercise. 2008; 40(1): 181.

11. Shimoda H, Seki E, Aitani M. Inhibitory effect of green coffee bean extract on fat accumulation and body weight gain in mice. BMC complementary and alternative medicine. 2006; 6(1): 9. doi: 10.1186/14726882-6-9.

12. Dray C, Daviaud D, Guigné C, Valet P, CastanLaurell I. Caffeine reduces TNF $\alpha$ up-regulation in human adipose tissue primary culture. Journal of physiology and biochemistry. 2007; 63(4): 329-36. 
13. Haskó G, Cronstein B. Methylxanthines and inflammatory cells. Handb Exp Pharmacol. 2011; 200: 457-68. doi: 10.1007/978-3-642-13443-2_18.

14. Naderi L, Sharifi G. Comparison of the Effect of 8 weeks Concurrent Training and Green Coffee Supplementation on Serum Adipsin and Insulin Resistance in Obese Women. Armaghane danesh. 2017; 22(5): 623-36.

15. Pourvaghar MJ, Shahsavar A, Bahram ME. The effect of a single bout of severe aerobic exercise on apolipoproteins $A, B$ and some serum lipid profiles. Journal (FEYZ). 2015;18(6):585-91.

16. Ketabipour SM. The effect of aerobic exercise in water on type B and A apoprotein and serum lipoprotein in obese and obese menopausal women. Journal of Arak University of Medical Sciences. 2013;No. 8, 44-52.

17. Banz WJ, Maher MA, Thompson WG, Bassett DR, Moore W, Ashraf M, et al. Effects of resistance versus aerobic training on coronary artery disease risk factors. Experimental Biology and Medicine. 2003; 228(4): 43440.

18. Ghorbanian B, Ghasemnian A. The Effects Of Interval Combined Endurance Training On Some Key Reverse Cholesterol Transport Factors In Boy Adolescents. URMIA MED J. 2015; 26(3): 227-36.
19. Ben Ounis O, Elloumi M, Makni E, Zouhal H, Amri $\mathrm{M}$, Tabka Z, et al. Exercise improves the ApoB/ApoA-I ratio, a marker of the metabolic syndrome in obese children. Acta Paediatr. 2010; 99(11): 1679-85. doi: 10.1111/j.1651-2227.2010.01920.x.

20. Yektayar M, Mohammadi S, Ahmadi Deharshid K, Khodamoradpour M. Comparison of the effects of resistance, endurance and combined exercises on lipid profile of non-athlete healthy middle aged men. SJKU. 2012; 16(4): 26-36.

21. Sugiura H, Sugiura H, Kajima K, Mirbod SM, Iwata $\mathrm{H}$, Matsuoka T. Effects of long-term moderate exercise and increase in number of daily steps on serum lipids in women: randomised controlled trial [ISRCTN21921919]. BMC Women's Health. 2002; 2(1): 3.

22. Kleemola P, Jousilahti P, Pietinen P, Vartiainen E, Tuomilehto J. Coffee consumption and the risk of coronary heart disease and death. Archives of internal medicine. 2000;160(22): 3393-400. 